\title{
COMMENTARY
}

\section{Possible new mechanism of cortisol action in female reproductive organs: physiological implications of the free hormone hypothesis}

\author{
C Yding Andersen \\ Laboratory of Reproductive Biology, Section 5712, University Hospital of Copenhagen, DK-2100 Copenhagen, Denmark \\ (Requests for offprints should be addressed to C Yding Andersen; Email: yding@rh.dk)
}

\begin{abstract}
The so-called free hormone hypothesis predicts that the biological activity of a given steroid correlates with the free protein-unbound concentration rather than with the total concentration (i.e. free plus protein-bound). Cortisol is a glucocorticoid with many diverse functions and the free hormone hypothesis seems to apply well to the observed effects of cortisol. The ovaries express glucocorticoid receptors and are affected by cortisol, but lack the necessary enzymes for cortisol synthesis. Ovarian follicles modulate the biological activity of cortisol by (1) follicular production of especially progesterone and $17 \alpha$-hydroxyprogesterone which, within the follicle, reach levels that displace cortisol from its binding proteins, in particular, cortisol-binding protein, making it available for biological action and (2) a developmental regulated expression of two types of $11 \beta$-hydroxysteroid dehydrogenase (i.e. $11 \beta-$ HSD type 1 and type 2), which oppose the action of one another, the $11 \beta-H S D$ type 2 predominantly inactivating
\end{abstract}

cortisol to cortisone, while $11 \beta-\mathrm{HSD}$ type 1 reverses this reaction. As a result, a high concentration of cortisol available for biological action is present in the preovulatory follicle just prior to ovulation and it has been suggested that cortisol may function to reduce the inflammatory-like reactions occurring in connection with ovulation.

This paper suggests (1) that the function of the oviduct is also affected by the high levels of free cortisol released in preovulatory follicular fluid at ovulation and (2) that formation and function of the corpus luteum benefits from a high local concentration of free cortisol, whereas the surrounding developing follicles may experience negative effects. If this hypothesis proves correct it may describe a new physiological mechanism by which cortisol interacts with the female reproductive organs, showing that the biologically active concentration of a steroid locally can be regulated to serve specific functions.

Journal of Endocrinology (2002) 173, 211-217

\section{Cortisol and the ovaries}

Glucocorticoids exert their effects in all parts of the body and are involved in a number of physiological processes. The ovary is also susceptible to the action of glucocorticoids; receptors for glucocorticoids are present and it is well known that the reproductive function may be impaired during periods of adrenal hyperactivity. In addition to a direct effect on the ovaries, glucocorticoids also affect ovarian function indirectly via the adrenalhypothalamo-pituitary axis. One of the prominent glucocorticoids affecting ovarian function is cortisol. Cortisol is not produced de novo by the ovaries (Omura \& Morohashi 1995) but transport takes place from the adrenal glands through the circulation.

\section{Cortisol and the free hormone hypothesis}

Cortisol reaches the ovaries in one of two forms, the majority is bound to plasma proteins and only a small fraction is free and unbound. The principal binding protein in the circulation is cortisol-binding protein (CBP). One molecule of CBP binds one molecule of cortisol with high affinity. Also albumin binds cortisol but with low affinity (Table 1). The third major protein transporting steroids is sex-hormone-binding globulin (SHBG) which, however, only binds cortisol with low affinity and is without physiological significance with regard to glucocorticoids (Dunn et al. 1981).

The biological activity of cortisol seems to be confined to the free unbound fraction, which is available for movement out of the capillaries and into cells, where it may either initiate a biological response or be cleared from the circulation in a variety of metabolic pathways (Rosner 1990). The free hormone hypothesis predicts that the biological activity of cortisol is proportional to the concentration of free hormone and not to the total concentration including the protein-bound fraction. Although this 
Table 1 Binding affinities of steroids for cortisol-binding protein (CBP), sex-hormone-binding globulin (SHBG) and albumin

\begin{tabular}{|c|c|c|c|}
\hline & $\begin{array}{l}\text { CBP } \\
\left(\mathrm{k} \times 10^{6} / \mathrm{M}\right)\end{array}$ & $\begin{array}{l}\text { SHBG } \\
\left(\mathrm{k} \times 10^{6} / \mathrm{M}\right)\end{array}$ & $\begin{array}{l}\text { Albumin } \\
\left(\mathrm{k} \times 10^{6} / \mathrm{M}\right)\end{array}$ \\
\hline Cortisol & 76 & $1 \cdot 6$ & $0 \cdot 003$ \\
\hline Cortisone & $7 \cdot 8$ & $2 \cdot 7$ & 0.005 \\
\hline Oestradiol & $0 \cdot 06$ & 680 & 0.060 \\
\hline Pregnenolone & $0 \cdot 18$ & 14 & 0.060 \\
\hline Progesterone & 24 & $8 \cdot 8$ & $0 \cdot 060$ \\
\hline $17 \alpha$-OH-progesterone & 55 & $9 \cdot 9$ & $0 \cdot 040$ \\
\hline Testosterone & $5 \cdot 3$ & 1600 & 0.040 \\
\hline
\end{tabular}

Values obtained from Dunn et al. (1981).

hypothesis may not be valid for all steroid hormones in every organ, there seems to be good evidence to suggest that it accounts for cortisol action in most situations (for review see Orth \& Kovacs 1998) as supported by the following studies: (1) A reduced in vivo activity of CBPbound cortisol (Slaunwhite et al. 1962), (2) a reduced suppressive effect of cortisol on mononuclear cell DNA synthesis in vitro in the presence of CBP (Ogawa et al. 1983), (3) cortisol bound to CBP avoids metabolic degradation (Bright 1995), (4) the mechanism that regulates cortisol production correlates with the free rather than the total concentration and (5) the concentration of free cortisol in the circulation is usually normal in the presence of abnormal CBP levels (Mendel 1989).

The function of steroid-binding proteins, therefore, is to act as a buffer reservoir of steroids present throughout the body that can readily be made available to the pool of free hormone by simple dissociation (Rosner 1990). The steroid-binding proteins reduce alterations in the free steroid level and maintain the level of free biologically active cortisol at a relative constant level. CBP is present in a relative constant concentration of around $700 \mathrm{nmol} / 1$, and exceeds the upper limit of the normal concentration range of cortisol (i.e. $550 \mathrm{nmol} / \mathrm{l}$ ). Consequently, in both normal men and women only a few percent of the total concentration of cortisol is free and unbound (Dunn et al.
1981) and this small concentration available for biological action therefore undertakes the normal physiological functions of cortisol.

\section{Modulation of cortisol levels within the ovaries}

The $11 \beta$-hydroxysteroid dehydrogenase (11 $\beta$-HSD) family of enzymes plays an important role in controlling the local tissue concentration of cortisol. Two distinct isoforms of $11 \beta$-HSD exist (i.e. $11 \beta$-HSD type 1 and type 2) (Michael et al. 1997, Tetsuka et al. 1997), 11 $\beta$-HSD type 2 predominantly inactivates cortisol to cortisone, while $11 \beta-H S D$ type 1 reverses this reaction predominantly converting cortisone to cortisol (Fig. 1) (Monder \& Lakshmi 1989, Mercer et al. 1993, Michael et al. 1997). The relative expression of the two types of $11 \beta-H S D$ in specific organs modifies cortisol exposure by interconversion between active and inactive glucocorticoids as seen in the kidney, liver, bone and adipose tissue. In the human, ovary expression of $11 \beta$-HSD types 1 and 2 is also well documented (Tetsuka et al. 1997, Smith et al. 2000, Yong et al. 2000). However, expression of $11 \beta$-HSD type 2 (i.e. inactivation of cortisol) is most abundant during the luteal phase in the corpus luteum (CL), and in non-luteinized granulosa cells from follicles before the mid-cycle surge of gonadotrophins. In contrast, expression of $11 \beta-H S D$ type 1 (i.e. formation of cortisol from cortisone) is only seen in granulosa cells from preovulatory follicles in response to the mid-cycle surge of gonadotrophins (Tetsuka et al. 1997, Smith et al. 2000, Yong et al. 2000). As observed in other organs (Escher et al. 1997), it has been suggested that release of cytokines like interleukin-1 $\beta$ and tumour necrosis factor- $\alpha$ regulates the expression of $11 \beta-$ HSD in rat granulosa cells and that these factors, in connection with the mid-cycle surge of gonadotrophins, up-regulates $11 \beta$ HSD type 1 expression (Hillier \& Tetsuka 1998). The expression of $11 \beta$-HSD types 1 and 2 actually fits well with the observed levels of total cortisol and cortisone in follicular fluid (FF), where cortisone seems to predominate before the mid-cycle surge of gonadotrophins, whereas

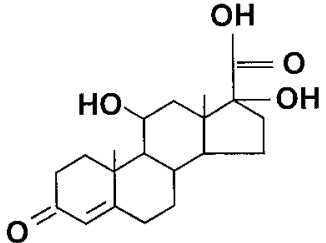

Cortisol

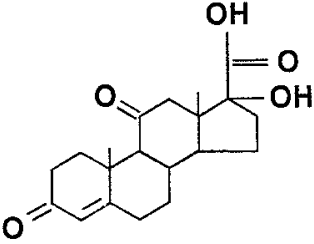

Cortisone

Figure 1 In the ovary, cortisol is inactivated through the action of $11 \beta$-hydroxysteroid dehydrogenase (HSD) type 2, which predominantly favours the formation of cortisone, whereas $11 \beta$-HSD type 1 reverses this process, predominantly catalysing the formation of cortisol from cortisone. 
Table 2 Average total and free concentrations (in $\mathrm{nmol} / \mathrm{l}$ ) of steroids in serum and preovulatory follicular fluid (FF) obtained from women undergoing in vitro fertilization (IVF) with exogenous gonadotrophins

\begin{tabular}{|c|c|c|c|c|c|c|}
\hline & Progesterone & $17 \alpha-O H-p r o g e s t e r o n e$ & Cortisol & Oestradiol & Testosterone & Androstenedione \\
\hline \multicolumn{7}{|l|}{ Total } \\
\hline Serum & 18 & 14 & 286 & $4 \cdot 2$ & $3 \cdot 9$ & $8 \cdot 4$ \\
\hline $\mathrm{FF}$ & 29700 & 6490 & 254 & 2480 & $8 \cdot 3$ & 58 \\
\hline \multicolumn{7}{|l|}{ Free } \\
\hline Serum & $\begin{array}{l}0 \cdot 4 \\
(2 \cdot 2 \%)\end{array}$ & $\begin{array}{l}0 \cdot 24 \\
(1 \cdot 7 \%)\end{array}$ & $\begin{array}{l}5 \cdot 7 \\
(2 \cdot 0 \%)\end{array}$ & $\begin{array}{l}0 \cdot 026 \\
(1 \cdot 1 \%)\end{array}$ & $\begin{array}{l}0 \cdot 032 \\
(0 \cdot 8 \%)\end{array}$ & $\begin{array}{l}0 \cdot 56 \\
(6 \cdot 7 \%)\end{array}$ \\
\hline FF & $\begin{array}{l}985 \\
(3 \cdot 3 \%)\end{array}$ & $\begin{array}{l}310 \\
(4 \cdot 8 \%)\end{array}$ & $\begin{array}{l}69 \\
(27 \%)\end{array}$ & $\begin{array}{l}83 \\
(3 \cdot 3 \%)\end{array}$ & $\begin{array}{l}0 \cdot 4 \\
(4 \cdot 8 \%)\end{array}$ & $\begin{array}{l}5 \cdot 6 \\
(9 \cdot 6 \%)\end{array}$ \\
\hline
\end{tabular}

Percentages given in parentheses for the free concentrations indicate concentrations of free steroid in relation to the total concentration.

Concentrations of free steroids were calculated using the computer simulation program Transport as described (Dunn et al. 1981), based on respective association constants between the steroids and binding proteins, and the total molar concentration of each of the steroid-protein complexes. Total concentations of CBP, SHBG, albumin, progesterone,

$17 \alpha-\mathrm{OH}$-progesterone, cortisol, oestradiol, testosterone and androstenedione were used as input.

higher levels of cortisol are seen in FF immediately prior to ovulation (Yding Andersen et al. 1999, Yong et al. 2000). This developmentally regulated pattern of $11 \beta-H S D$ types 1 and 2 has formed the basis to suggest that cortisol serves an anti-inflammatory role during ovulation, promoting rapid healing of the wound left by follicular rupture (Hillier \& Tetsuka 1998).

\section{Cortisol in human preovulatory FF}

Increased levels of circulating free cortisol may lead to pathological conditions as in Cushing's syndrome. However, the fluid of preovulatory follicles collected immediately before ovulation exhibits levels of free cortisol exceeding the serum levels as seen in Cushing's syndrome (Yding Andersen \& Hornnes 1994, Harlow et al. 1997). The high levels of cortisol available for biological action in preovulatory FF can be ascribed to two independent mechanisms.

Preovulatory FF contains levels of progesterone and 17 $\alpha$-hydroxy-progesterone (17 $\alpha$-OH-progesterone) more than a thousand times higher than that seen in the circulation and may reach average levels of around $30 \mu \mathrm{mol} / 1$ and $5-10 \mu \mathrm{mol} / 1$ respectively (Table 2 ). CBP also binds progestins with high affinity. The affinity constant of progesterone for $\mathrm{CBP}$ is around three times lower than for cortisol itself, whereas $17 \alpha-\mathrm{OH}-$ progesterone approaches the binding affinity of cortisol (76 versus $\left.55 \times 10^{6} / \mathrm{M}\right)($ Table 1). A significant displacement of cortisol from CBP would be expected by such high concentrations of progesterone and $17 \alpha-\mathrm{OH}-$ progesterone, which both exceed the total level of cortisol by more than one order of magnitude.

Furthermore, in response to the mid-cycle surge of gonadotrophins, the preovulatory follicle reduces the expression of $11 \beta-\mathrm{HSD}$ type 2 , while $11 \beta$-HSD type 1 is up-regulated favouring enhanced cortisol production at the expense of inactive cortisone (Tetsuka et al. 1997). Two additional mechanisms may participate in creating high levels of free cortisol in follicles close to ovulation. (1) Proteolytic enzymes generated in order for the oocyte to be released from the follicle may actually cleave CBP and cause release of cortisol. Such a mechanism has been suggested for targeted delivery of cortisol to sites of inflammation (Hammond et al. 1990, Hammond 1997) and (2) using human kidney cortex microsomes it has been shown that progesterone inhibits the function of $11 \beta-\mathrm{HSD}$ type $2\left(\mathrm{IC}_{50}=4 \cdot 8 \times 10^{-8} \mathrm{~mol} / \mathrm{l}\right)$ (Quinkler et al. 1999). The activity of $11 \beta-\mathrm{HSD}$ type 2 in preovulatory follicles may consequently be reduced because of the high concentrations of progesterone.

Collectively, it has been estimated that the concentration of free cortisol in preovulatory FF reaches levels ten times higher than the corresponding values in serum (Table 2). We found that almost half of the cortisol in preovulatory FF is either free or bound with low affinity to albumin (Yding Andersen \& Hornnes 1994). Harlow et al. (1997) largely confirmed these findings using an ultrafiltration technique and found around $15 \%$ of the cortisol in preovulatory FF to be free, and that free concentrations on average exceeded those observed in patients with Cushing's syndrome.

A precise physiological function of these high levels of biologically active cortisol is not yet clear. However, ovulation has been described as a controlled inflammatory reaction involving cytokine synthesis, prostaglandin and histamine release in combination with production of proteolytic enzymes (Espey \& Lipner 1994). Once proteolytic degradation has weakened the follicle wall and a passage has been established allowing the oocyte to be expelled from the follicle, mechanisms to reduce and 
confine these inflammatory processes must be in place to prevent further damage to the follicle and the developing CL. It has been suggested that the local high levels of free cortisol participate in these processes by limiting tissue damage and by acting as anti-inflammatory agents (Yding Andersen \& Hornnes 1994, Hillier \& Tetsuka 1998, Yong et al. 2000).

\section{A physiological function of FF released from the preovulatory follicle during ovulation on the oviduct?}

Maximum concentrations of intrafollicular levels of progesterone and $17 \alpha-\mathrm{OH}$-progesterone are reached just prior to the actual release of the oocyte cumulus complex to the oviduct. The fluid expelled from the follicle therefore contains high concentrations of free cortisol. The oviduct takes up part of this fluid, the remainder is found in the peritoneal cavity in the vicinity of the oviduct.

In women, the preovulatory follicle usually contains around $6-8 \mathrm{ml}$. The actual total amount of both progesterone and oestradiol in such fluid exceeds the total amount found in the entire circulation at the time of ovulation (Yding Andersen et al. 1992). Despite this fact, the follicular release of oestradiol and progesterone is not reflected in the circulation. Consequently, in connection with ovulation, the oviduct is probably exposed to high concentrations of progesterone and $17 \alpha-\mathrm{OH}-$ progesterone, and also to high levels of free cortisol. Do these high levels of free cortisol in FF exert a physiological function on the oviduct in connection with ovulation?

In contrast to the uterus, the oviduct seems to avoid infiltration of leukocytes due to the presence of spermatozoa (for review see Harper 1994). High numbers of leukocytes are attracted to the uterus by the presence of spermatozoa, which seems to ensure that the uterus is devoid of spermatozoa within a 24-h period after intercourse (for review see Harper 1994). In contrast, the oviduct may harbour fertilizable spermatozoa for a much longer period of around $85 \mathrm{~h}$. The mechanism by which the oviduct avoids such infiltration has not yet been clarified as illustrated by the considerations raised by Yanagimachi (1994) during his discussion on the function of the zona pellucida: 'Incidentally, the oviductal luminal fluid in which preimplantation embryos develop is usually free of leukocytes and microorganisms. The oviduct may thus possess some mechanisms that inhibit invasion and/or survival of such invasive cells and organisms'.

With this background, it is proposed that the local high concentrations of free cortisol in the oviduct derived from FF released at ovulation participate in the protection of the oviduct from invasion by leukocytes, allowing fertilization and early embryo development to occur in a proper manner. In addition, the oviduct produces prostaglandins which, in a complex manner, affect the contractility and the transfer of the oocyte/embryo to the uterus. It seems that prostaglandin $\mathrm{E}$ and prostaglandin $\mathrm{F}_{2 \alpha}$ exert different functions (for review see Harper 1994). It is known that cortisol decreases production of prostaglandins, and it may be speculated that the high levels of free cortisol derived from the FF participate in the complex interactions between the different types of prostaglandin in the oviduct.

\section{Does biologically active cortisol affect the function of the CL?}

The newly formed CL produces progesterone at its highest level under appropriate stimulation by luteinizing hormone. Actually, taking its small size into account, the CL is the most active steroidogenic tissue in humans, producing as much as $40 \mathrm{mg}$ progesterone per day during the mid-luteal phase of the menstrual cycle (for review see Carr 1998). Therefore, the CL and the immediate surroundings of the ovary experience high levels of progestins locally. These high levels of progesterone and $17 \alpha-\mathrm{OH}-$ progesterone make it conceivable that the concentration of free cortisol locally is increased as well, resembling the milieu of the preovulatory follicle, where progestins compete with cortisol for binding to CBP. Could these potentially high levels of free cortisol in the vicinity of the $\mathrm{CL}$ exert effects on the CL itself and the surrounding subordinate follicles?

The newly formed CL is characterized by the formation of new capillary networks. Capillary invasion of the granulosa cell layer begins 2 days after ovulation. Maximal capillary dilation is attained 7-8 days after ovulation and haemorrhage can occur any day in the CL (for review see Carr 1998). It may be vital to reduce and limit the inflammatory reactions which have been initiated in the cells that remain in the ovary after ovulation and induce a process of wound healing. Likewise, there is a risk of haemorrhage affecting the function of CL negatively. It is proposed that the formation and function of the CL benefit from the presence of a high local level of biologically active cortisol, which may reduce or prevent unwanted inflammatory events from taking place. Therefore, this suggestion extends a possible physiological function of high levels of free cortisol to include not only the ovulatory process but also the establishment and function of the CL.

Cells of the CL, as such, may not require high local levels of cortisol and they may express high levels of $11 \beta-H S D$ type 2 as a defence mechanism. However, the importance of this defence mechanism may be reduced by the possible inhibitory activity of progesterone on $11 \beta-$ HSD type 2 activity (Quinkler et al. 1999).

Conditions in the CL may also affect the neighbouring ovarian tissue. It has been suggested that the high levels of progestins exert paracrine effects reducing the developmental potential locally of follicles before they reach 
gonadotrophin-dependent follicular growth (Moore \& Greenwald 1974, Fukuda et al. 1980, Schreiber et al. 1981). Furthermore, women who were followed for two consecutive menstrual cycles had a significantly higher chance of conceiving when ovulation of the second cycle occurred from the ovary opposite to the previous one compared with two consecutive ovulations from the same ovary (Fukuda et al. 1999). It was suggested that progesterone production of the CL in the first cycle exerted a local negative effect on the developing follicles of that ovary, which became manifest as a decreased pregnancy rate during in vitro fertilization (IVF) treatment in connection with the second cycle. An alternative explanation may be that a high local concentration of progestins is likely to cause high local levels of free cortisol which, in fact, may cause the attenuated developmental potential of growing follicles. In support of this hypothesis, studies in rats showed that oocytes from immature follicles express the

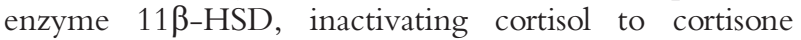
(Benediktsson et al. 1992). Furthermore, reduced exposure to cortisol seems to improve follicular development before the preovulatory stage (Michael \& Cooke 1994).

Taken together, the high levels of progestins in the CL may create high local levels of cortisol, which may reduce unwanted inflammatory effects that can occur due to haemorrhage in connection with formation of new capillary networks in the CL. Cells of the CL and the growing follicles in the vicinity of the CL try to dampen the effects of biologically active cortisol by expression of $11 \beta-\mathrm{HSD}$ type 2 .

\section{Biological activity of $17 \alpha-\mathrm{OH}-$ progesterone and a possible new therapeutic principle for anti- inflammatory actions of cortisol}

Whereas progesterone has several well-documented endocrinological effects in female reproductive organs, separate effects of $17 \alpha-\mathrm{OH}$-progesterone have not been ascribed (Lipsett 1986). Actually, 17a-OH-progesterone is normally regarded as a metabolite in adrenal and ovarian steroidogenesis with little, if any, biological activity. This is somewhat surprising since $17 \alpha-\mathrm{OH}$-progesterone is a steroid which is produced by the preovulatory follicle and by the CL in considerable amounts, reaching 10-20\% of the level of progesterone. As shown in Table 2, levels in preovulatory FF may actually reach $5-10 \mu \mathrm{mol} / 1$. Since these levels are at least one order of magnitude higher than the total levels of cortisol, $17 \alpha-\mathrm{OH}$-progesterone may function as a ligand which, with almost equal affinity, displaces cortisol from CBP and, under certain circumstances, enhances the biological activity of cortisol.

If a locally increased concentration of free biologically active cortisol exerts physiological actions within the preovulatory follicle and the CL, a similar principle may be applied to treat local inflammatory reactions elsewhere in the body. Reactions to confine inflammatory reactions are often alleviated by treatment with depot preparations of glucocorticoids with which, however, side-effects may result in systemic effects. Instead, a depot of $17 \alpha-\mathrm{OH}-$ progesterone with a slow release may be used. If local high concentrations of $17 \alpha-\mathrm{OH}$-progesterone can be created, cortisol is likely to be displaced from CBP as it passes by, increasing the local biological activity of cortisol, allowing for a local anti-inflammatory action. When the concentration of $17 \alpha-\mathrm{OH}$-progesterone is decreased (diluted out) as the distance from the site of the inflammatory reaction increases, the concentration of free cortisol will also be decreased as it rebinds to CBP. Consequently, the overall concentration of cortisol will not be increased and the systemic effects of excess cortisol may be avoided. An additional advantage may be that $17 \alpha-\mathrm{OH}$-progesterone is apparently a physiological compound without or with only low biological activity, and which will not undertake undesired actions of its own. In addition, the body (at least the woman's) is well accustomed to high concentrations of $17 \alpha-\mathrm{OH}$-progesterone, and is capable of dealing with it metabolically. In fact previous studies support this idea, since $17 \alpha-\mathrm{OH}$-progesterone is well known for its good tolerability, and substantial therapeutic doses can be administered without concern about local reactions (Reifenstein 1957).

In patients with 21-hydroxylase deficiency, levels of $17 \alpha-\mathrm{OH}$-progesterone are grossly elevated and indeed women are known to have fertility problems. The high levels of $17 \alpha-\mathrm{OH}$-progesterone result from an uninhibited pituitary adrenocorticotrophin secretion due to the deficient cortisol secretion. Appropriate glucocorticoid treatment reduces levels of both $17 \alpha-\mathrm{OH}$-progesterone and androgens to physiological or near physiological levels. As a consequence, such patients with congenital adrenal hyperplasia are unlikely to represent a model with which the in vivo effects of a concomitant presence of high levels of $17 \alpha-\mathrm{OH}$-progesterone and normal levels of cortisol can be evaluated.

\section{New mechanisms for the action of cortisol in female reproductive organs}

The above considerations suggest that the level of biologically active cortisol in female reproductive organs is regulated by an interplay of two different mechanisms. First, the local concentration of free cortisol is enhanced by ovarian progestins, especially seen during conditions with high local levels of progesterone and $17 \alpha-\mathrm{OH}-$ progesterone, such as in preovulatory follicles just prior to ovulation and in the CL. Secondly, the selective expression of $11 \beta-H S D$ types 1 and 2 promotes high levels of cortisol during the mid-cycle surge of gonadotrophins, whereas reduced levels are maintained throughout the rest of the menstrual cycle. 
Thus, a local regulation of the concentration of biologically active cortisol may prove to be an important physiological mechanism by which glucocorticoids affect female reproductive organs, and provide a tool for a more detailed understanding of interactions between glucocorticoids and female reproductive organs. In addition, if these hypotheses prove correct, for which indeed future research is needed, they describe a mechanism by which the biologically active concentration of a steroid locally is regulated to serve specific functions. Application of this principle to steroid action may provide a more detailed understanding of steroid effects in other organs. In addition, it may describe a new therapeutic principle for the antiinflammatory actions of cortisol in which depot preparations of $17 \alpha-\mathrm{OH}$-progesterone or another compound with high affinity towards CBP locally may displace cortisol from CBP.

\section{References}

Benediktsson R, Yau JLW, Low S, Brett LP, Cooke BE, Edwards CR \& Seckl JR 1992 11ß-Hydroxysteroid dehydrogenase in the rat ovary: high expression in the oocyte. Journal of Endocrinology 135 53-58.

Bright GM 1995 Corticosteroid-binding globulin influences kinetic parameters of plasma cortisol transport and clearance. Journal of Clinical Endocrinology and Metabolism 80 770-775.

Carr BR 1998 Disorders of the ovaries and female reproductive tract. In Endocrinology, edn 9, pp 715-818. Eds JD Wilson, DW Foster, HM Kronenberg \& P Reed Larsen. Philadelphia, USA: WB Saunders Co.

Dunn JF, Nisula BC \& Rodbard D 1981 Transport of steroid hormones: binding of 21 endogenous steroid to both testosteronebinding globulin and corticosteroid-binding globulin in human plasma. Journal of Clinical Endocrinology and Metabolism 53 58-68.

Escher G, Galli I, Vishwanath BS, Frey BM \& Fery FJ 1997 Tumor necrosis factor alpha and interleukin 1 beta enhance the cortisone/ cortisol shuttle. Journal of Experimental Medicine 186 189-198.

Espey LL \& Lipner H 1994 Ovulation. In The Physiology of Reproduction, edn 2, pp 725-813. Eds E Knobil \& JD Neill. New York: Raven Press.

Fukuda M, Katayama K \& Tojo S 1980 Inhibitory effect of progesterone on follicular growth and induced superovulation in the rat. Archives of Gynaecology 230 77-87.

Fukuda M, Fukuda K, Yding Andersen C \& Byskov AG 1999 Anovulations in an ovary during two menstrual cycles enhance the pregnancy potential of oocytes matured in that ovary during the following third cycle. Human Reproduction 14 96-100.

Hammond GL 1997 Determinants of steroid hormone bioavailability. Biochemical Society Transactions 25 577-582.

Hammond GL, Smith CL, Paterson NAM \& Sibbald WJ 1990 A role for corticosteroid-binding globulin in delivery of cortisol to activated neutrophils. Journal of Clinical Biochemistry and Metabolism 71 34-39.

Harlow CR, Jenkins JM \& Winston RML 1997 Increased follicular fluid total and free cortisol levels during the luteinizing hormone surge. Fertility and Sterility 68 48-53.

Harper MKJ 1994 Gamete and zygote transport. In The Physiology of Reproduction, edn 2, pp 123-188. Eds E Knobil \& JD Neill. New York: Raven Press.

Hillier SG \& Tetsuka M 1998 An anti-inflammatory role for glucocorticoids in the ovaries? Journal of Reproductive Immunology 39 $21-27$.
Lipsett M 1986 Steroid hormones. In Reproductive Endocrinology: Physiology, Pathophysiology and Clinical Management, edn 2, pp 140-153. Eds SSC Yen \& RB Jaffe. Philadelphia, USA: WB Saunders Co.

Mendel CM 1989 The free hormone hypothesis: a physiologically based mathematical model. Endocrine Reviews 10 232-274.

Mercer W, Obeyeskere V, Smith R \& Krozowski Z 1993 Characterization of $11 \beta \mathrm{HSD} 1 \mathrm{~B}$ gene expression and enzyme activity. Molecular and Cellular Endocrinology 92 247-251.

Michael AE \& Cooke BA 1994 A working hypothesis for the regulation of steroidogenesis and germ cell development in the gonads by glucocorticoids and $11 \beta$-hydroxysteroid dehydrogenase (11ßHSD). Molecular and Cellular Endocrinology 100 $55-63$.

Michael AE, Evagelatou M, Norgate DP, Clarke RJ, Antoniw JW, Stedman BA, Brennan A, Welsby R, Bujalska I, Stewart PM \& Cooke BA 1997 Isoforms of $11 \beta$-hydroxysteroid dehydrogenase in human granulosa-lutein cells. Molecular and Cellular Endocrinology $13243-52$.

Monder C \& Lakshmi V 1989 Evidence for kinetically distinct forms of corticosteroid 11 $\beta$-hydroxysteroid dehydrogenase in rat liver microsomes. Journal of Steroid Biochemistry 32 77-83.

Moore PJ \& Greenwald GS 1974 Effect of hypophysectomy and gonadotropin treatment on follicular development and ovulation in the hamster. American Journal of Anatomy 139 37-39.

Ogawa K, Sueda K \& Matsui N 1983 The effect of cortisol, progesterone and transcortin on phytohemagglutinin-stimulated human blood mononuclear cells and their interplay. Journal of Clinical Endocrinology and Metabolism 56 121-126.

Omura T \& Morohashi K 1995 Gene regulation of steroidogenesis. Journal of Steroid Biochemistry and Molecular Biology 53 19-25.

Orth DN \& Kovacs WJ 1998 The adrenal cortex. In Endocrinology, edn 9, pp 517-664. Eds JD Wilson, DW Foster, HM Kronenberg \& P Reed Larsen. Philadelphia, USA: WB Saunders Co.

Quinkler M, Johanssen S, Grosmann C, Bahr V, Muller M, Oelkers W \& Diederich S 1999 Progesterone metabolism in the human kidney and inhibition of $11 \beta$-hydroxysteroid dehydrogenase type 2 by progesterone and metabolites. Journal of Clinical Endocrinology and Metabolism 84 4165-4171.

Reifenstein EC 1957 Induction of marked as well as prolonged biological activity by esterification. Fertility and Sterility $\mathbf{8}$ 50-79.

Rosner W 1990 The functions of cortisol-binding globulin and sex-hormone-binding globulin: recent advances. Endocrine Reviews 11 80-91.

Schreiber JR, Nakamura K \& Erickson GF 1981 Progestins inhibit FSH-stimulated granulosa estrogen production at a post-cAMP site. Molecular and Cellular Endocrinology 21 161-170.

Slaunwhite WR, Lockie GN, Back N \& Sandberg AA 1962 Inactivity in vivo of transcortin-bound cortisol. Science $\mathbf{1 3 5}$ 1062-1063.

Smith MP, Mathur RS, Keay SD, Hall L, Hull MGR \& Jenkins JM 2000 Periovulatory human oocytes, cumulus cells, and ovarian leukocytes express type 1 but not type $211 \beta$ hydroxysteroid dehydrogenase RNA. Fertility and Sterility $\mathbf{7 3}$ 825-830.

Tetsuka M, Thomas FJ, Thomas MJ, Anderson RA, Mason JI \& Hillier SG 1997 Differential expression of messenger ribonucleic acids encoding 11ß-hydroxysteroid dehydrogenase types 1 and 2 in human granulosa cells. Journal of Clinical Endocrinology and Metabolism 82 2006-2009.

Yanagimachi R 1994 Mammalian fertilisation. In The Physiology of Reproduction, edn 2, pp 189-317. Eds E Knobil \& JD Neill. New York: Raven Press.

Yding Andersen C \& Hornnes P 1994 Intrafollicular concentrations of free cortisol close to follicular rupture. Human Reproduction 9 1944-1949. 
Yding Andersen C, Westergaard LG, Sinosich MJ \& Byskov AG 1992 Human preovulatory follicular fluid: inhibin and free steroids related to optimal follicular maturation in ovarian stimulation regimes and possible function in ovulation. Human Reproduction 7 765-769.

Yding Andersen C, Morineau G, Fukuda M, Westergaard LG, Ingerslev HJ, Fiet J \& Byskov AG 1999 Assessment of the follicular cortisol:cortisone ratio. Human Reproduction 14 1563-1568.
Yong PYK, Thong KJ, Andrew R, Walker BR \& Hillier SG 2000 Development-related increase in cortisol biosynthesis by human granulosa cells. Journal of Clinical Endocrinology and Metabolism $\mathbf{8 5}$ 4728-4733.

Received 11 January 2002

Accepted 17 January 2002 